\title{
An arthroscopic repair technique for meniscal tear using a needle and suture: outside-in transfer all-inside repair
}

\author{
Zhiqiang Wang ${ }^{1,2+}$, Yan Xiong ${ }^{1 \dagger}$, Xin Tang ${ }^{1}$, Qi Li ${ }^{1}$, Zhong Zhang ${ }^{1}$, Jian $\mathrm{Li}^{i^{* \dagger}}$ and Gang Chen ${ }^{1^{* \dagger}}$
}

\begin{abstract}
Background: At present, most repair techniques for meniscal tears fix the meniscus directly over the capsule. This changes the normal anatomy and biomechanics and limits the activity of the meniscus during motion. We introduce an arthroscopic repair technique by suturing the true meniscus tissue without the capsule and subcutaneous tissue.

Methods: After confirmation of a tear, a custom-designed meniscal repair needle first penetrates percutaneously, crossing the capsular portion and the torn meniscus, and exits from the femoral surface of one side of the torn meniscus. Then a No. 2 PDS suture is passed through the needle and retrieved through the arthroscopy portal. Next, the needle is withdrawn to the synovial margin of the meniscus and is reinserted, exiting the femoral surface of the other side of the torn meniscus. The suture is pulled out through the same portal with a grasper. Finally, arthroscopic knotting is performed.

Results: We had 149 cases of meniscal tears repaired with this outside-in transfer all-inside technique since July 2016.

Conclusions: It is a simple, minimally invasive, and economical procedure that is appropriate for most parts of the meniscus except the posterior horn of the lateral meniscus, and it can be used to fix torn meniscus tissue firmly while also preserving the inherent activity of the meniscus.
\end{abstract}

Keywords: All-inside, Outside-in, Knee, Meniscus, Suture repair

\section{Background}

Meniscal injuries are one of the most common injuries in sport medicine. The mean annual incidence of meniscal lesions per 10,000 inhabitants was 9.0 in males and 4.2 in females [1]. Meniscectomy increases the risk of developing osteoarthritis $(\mathrm{OA})$ of the knee significantly after 20 years [2]. Meniscal repairs are preferable over partial or total meniscectomies as they aim to restore a functional meniscus and possibly prevent early degenerative changes.

Many meniscal repair techniques such as outside-in, inside-out, and all-inside have been described for the treatment of these tears [3-7]. The outside-in technique

\footnotetext{
* Correspondence: hxlijian.china@163.com; drchengang@foxmail.com

'Zhiqiang Wang and Yan Xiong contributed equally to this work, Jian Li and

Gang Chen contributed equally to this work.

'Department of Orthopaedic Surgery, West China Hospital, Sichuan

University, No. 37, Guoxue Alley, Chengdu 610041, China

Full list of author information is available at the end of the article
}

is an option for anterior and middle-segment meniscal tears, but one disadvantage of this technique is that an additional $1-2 \mathrm{~cm}$ skin incision is required, and knots are tied subcutaneously over the capsule [8]. The goldstandard technique for meniscal repair has been the inside-out technique [9]. Some problems that are specific to this approach include the need for an accessory incision, and potential injuries to the medial saphenous, peroneal nerve, or lateral popliteal neurovascular bundle [10]. The all-inside repair technique can be used to repair the posterior horns and middle segments of the meniscus; however, this technique requires a special meniscal repair device, is expensive, and increases the risk of posterior lateral tears to the neurovascular bundle [11]. Furthermore, several material-related complications have been reported for the all-inside repair technique [12-14]. A systematic review and meta-analysis reported

(c) The Author(s). 2019 Open Access This article is distributed under the terms of the Creative Commons Attribution 4.0 International License (http://creativecommons.org/licenses/by/4.0/), which permits unrestricted use, distribution, and reproduction in any medium, provided you give appropriate credit to the original author(s) and the source, provide a link to the Creative Commons license, and indicate if changes were made. The Creative Commons Public Domain Dedication waiver (http://creativecommons.org/publicdomain/zero/1.0/) applies to the data made available in this article, unless otherwise stated. 
that the pooled rate of meniscal repair failure (reoperation or clinical failure) was $23.1 \%$ (131 of 566), which was greater than the five-year failure rates for all of the techniques that were investigated [15]. Many complications associated with meniscal repair have been reported the literature [16-19]. Reducing the risk of surgery and complications has always been the goal of surgeons. The development of a meniscus suture method that can increase meniscal healing and reduce complications is therefore desirable [20].

Here, we report an arthroscopic repair technique in the treatment of meniscal tears for most parts of the meniscus except for the posterior horn of the lateral meniscus. This technique could be used to suture the true meniscus tissue without the capsule and subcutaneous tissue, and could preserve the normal biomechanics of the meniscus during motion.

\section{Methods}

The patient was positioned for standard knee arthroscopy. Routine diagnostic arthroscopy using the standard anterolateral and anteromedial portals was performed. After confirmation of a tear, the meniscal tear site, size, pattern, vascularity, stability, tissue quality, and associated pathology within the knee joint were recorded. Tears located in the red-red and red-white zones can heal, and therefore can be repaired [21]. Before sewing, the tear site was debrided with a $3.5 \mathrm{~mm}$ full-radius motorized shaver (Dyonics; Smith \& Nephew, Andover, MA, USA) and rasped to encourage healing through the anteromedial portal. Next, the outside-in transfer allinside repair technique was applied. First, on the skin near the tear site, a custom-designed meniscal repair needle (Fig. 1) penetrated the capsular portion, crossing the tibial surface of the meniscus, and then exited the femoral surface of one side of the torn meniscus. Secondly, a No. 2 PDS (Ethicon, Sommerville, NJ, USA) suture was passed through the meniscal repair needle, and the suture tip was retrieved through the arthroscopy portal using a grasper (Fig. 2a). Thirdly, the needle was withdrawn carefully along the suture to the synovial margin of the meniscus inside the capsule and reinserted upwards without penetrating the meniscus tissue, exiting the femoral surface of the other side of the torn meniscus. The suture that was folded over the needle tip inside the joint was pulled out through the same portal with a grasper (Fig. 2b). Here, the outside-in repair technology was successfully converted to an all inside knotting technology (Fig. 2c). Next, the two limbs of the suture were tensioned simultaneously to achieve satisfactory reduction of the torn meniscus under arthroscopic visualization to form a Samsung Medical Center sliding knot inside the joint (Fig. 2d). Furthermore, additional three or four half-hitch knots with alternating posts on reverse throws were made to secure the knot. The knot was positioned on the synovial side such that the tied knot was positioned towards the peripheral rim portion of the meniscosynovial junction to prevent articular cartilage erosion of the femoral condyle during motion (Fig. 2e). After the knot was tied, the tension was
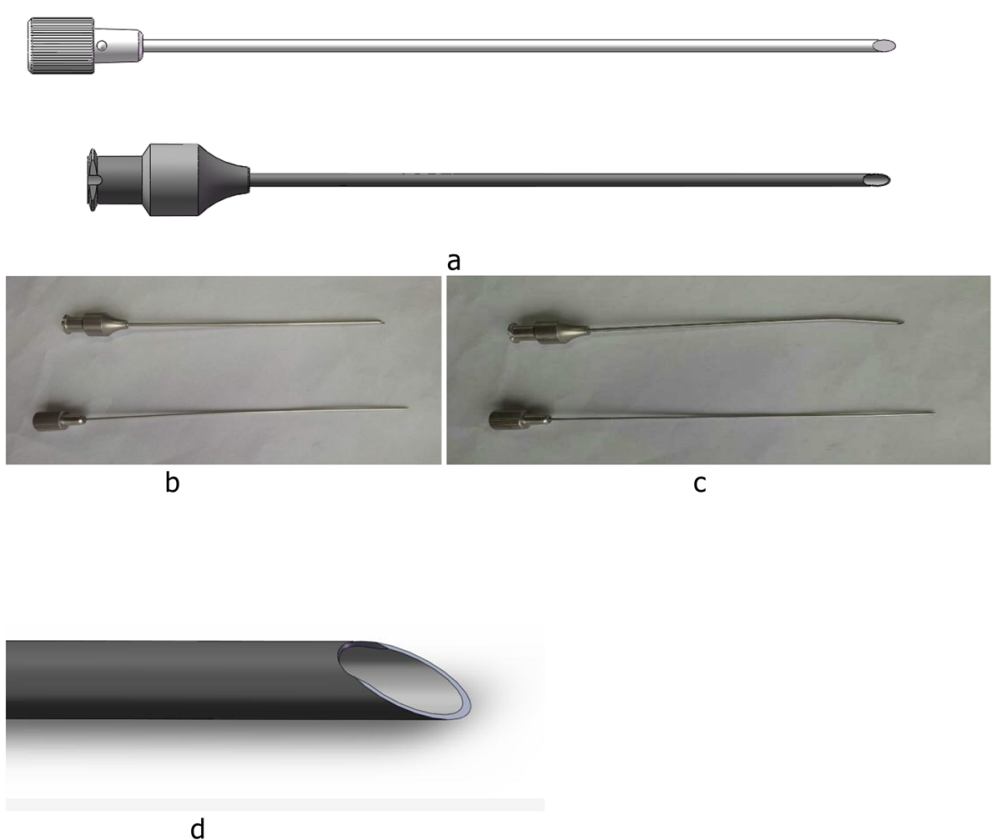

Fig. 1 Design drawings (a) and physical maps are shown for straight (b) and curved (c) custom-designed meniscal repair needles. A part of the tip is designed to be blunt, which can protect the suture material from being cut by the beveled needle tip (d) 


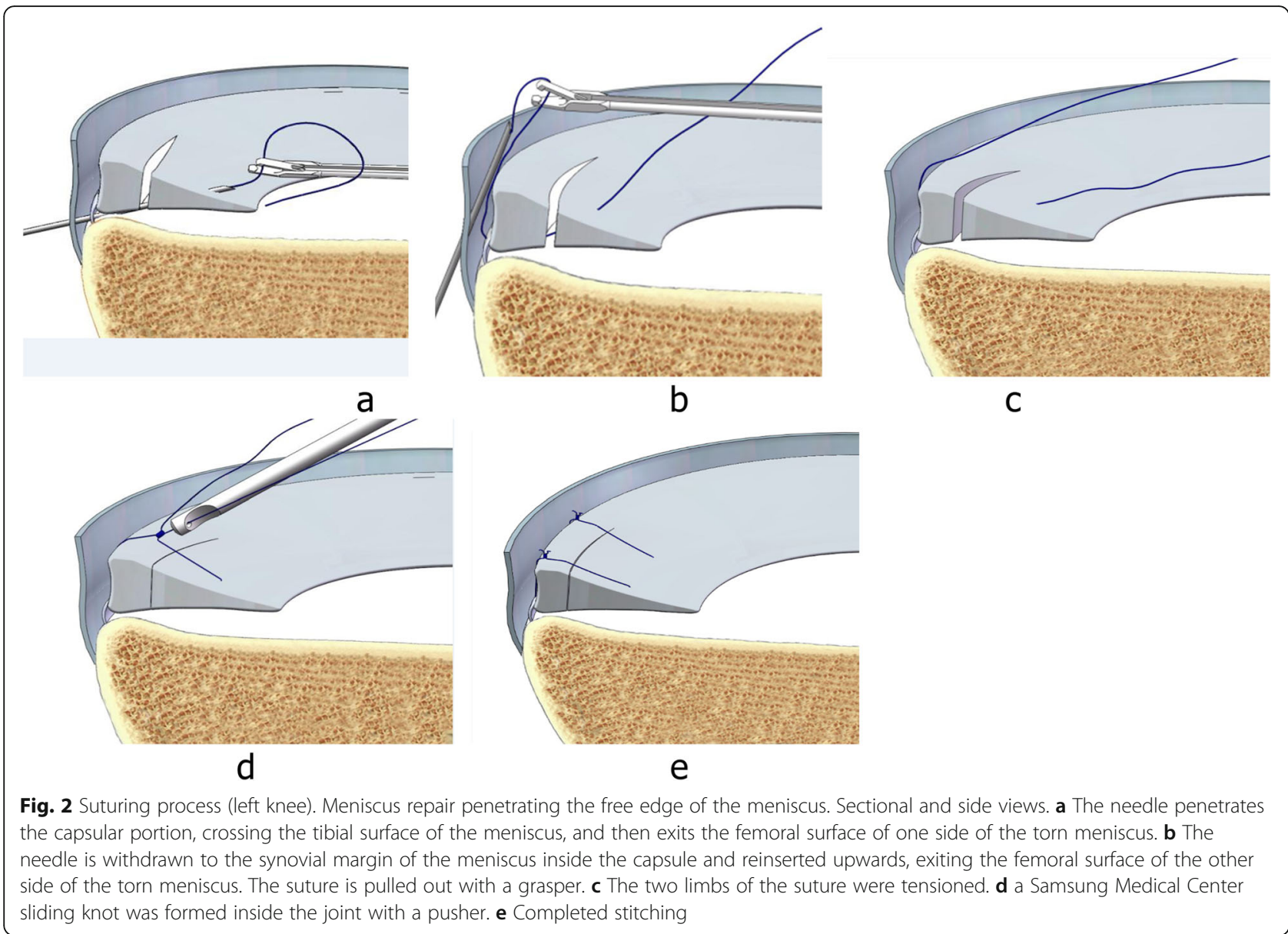

confirmed with a probe via arthroscopic visualization, and a second knot was made. The distance between the two knots is usually $6-8 \mathrm{~mm}$ depending on the type of meniscal tear (Fig. 3). The procedure (Additional file 1: Video S1) is repeated as often as necessary to yield a stable meniscal repair. Care was taken to avoid meniscal tissue eversion by appropriately adjusting the knot tension and the suture position. When the procedure is completed, the full range of motion should be performed at least 20 times to assess the reliability of the suture and yield more accurate anatomic reduction. Here, we outlined the vertical suture technique of the meniscus. A horizontal suture technique could be performed in the similar way if necessary.

According to the type of meniscal tear, there are two suture types: one that penetrates the free edge of the meniscus (Fig. 2), and one that does not penetrate the free edge of the meniscus (Fig. 4). For tears of the posterior horn of the medial meniscus, the needle can be guided by a K-wire using the inside-out technique because of the narrow joint space (Fig. 5). This technique should not be used for repairing the posterior horn of

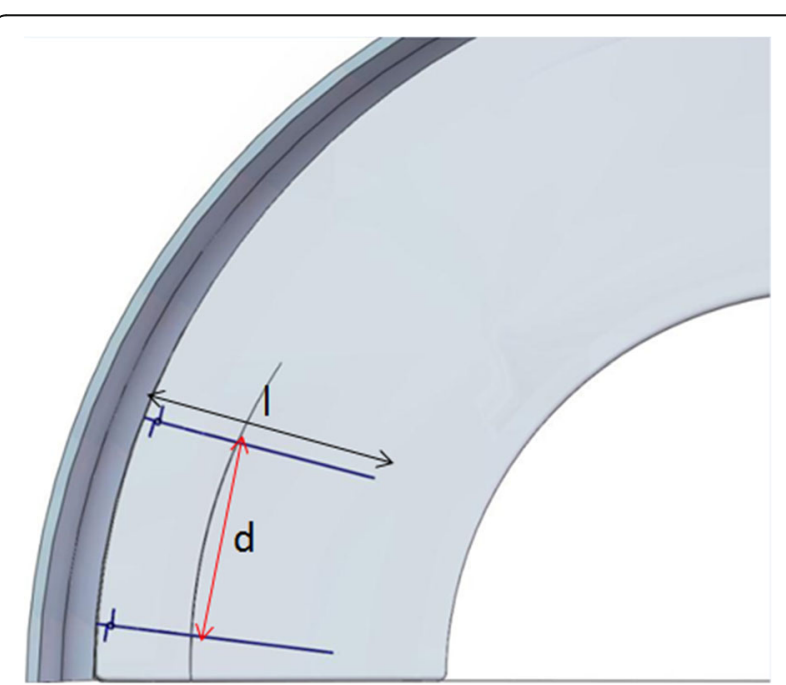

Fig. 3 The distance between the two knots (d) is equal to the length of the suture (I).(left knee) 


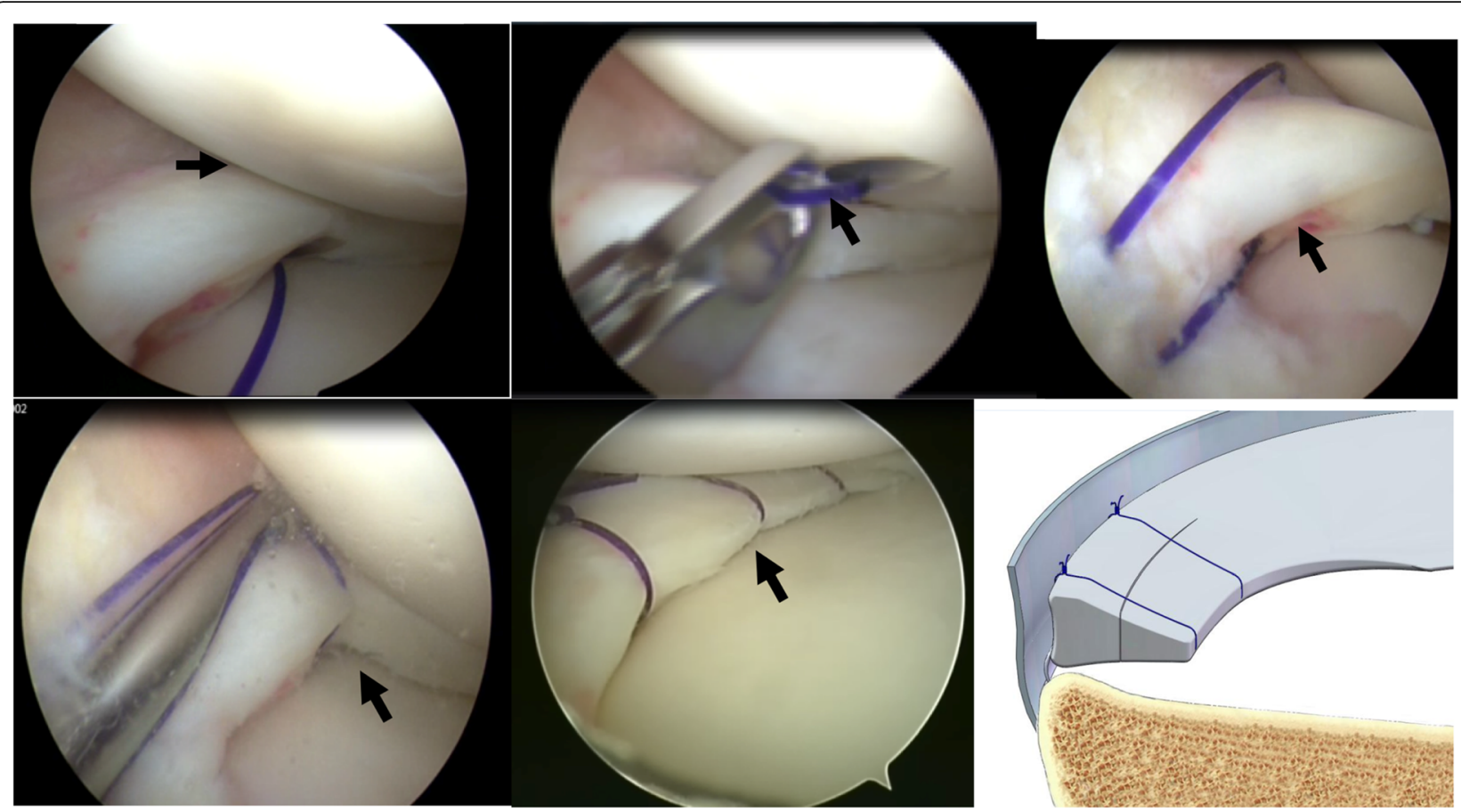

Fig. 4 Suturing process of the posterior horn of the medial meniscus (left knee). Meniscus repair without penetrating the meniscus. Arthroscopic view. a The needle penetrates the capsular portion, along the tibial surface of the meniscus into the joint cavity. $\mathbf{b}$ The needle is withdrawn to the synovial margin of the meniscus inside the capsule and reinserted upwards, exiting the femoral surface of the other side of the torn meniscus. The suture is pulled out with a grasper. c The two limbs of the suture were tensioned (d) a Samsung Medical Center sliding knot was formed inside the joint with a pusher. e Completed stitching. f Side view

the lateral meniscus considering the potential risks of injury to neurovascular structures.

During the postoperative period, all patients were instructed to perform quadriceps-setting exercises. After immobilization for 2 weeks, the knee flexion and extension exercises as well as partial weight-bearing were allowed.

\section{Results}

We had 149 cases of meniscal tears repaired with this outside-in transfer all-inside technique since July 2016. The mean age of the patients was 25.4 years (range, 1546 years). All patients were able to perform the full range of motion at least 20 times, and the knots did not loosen or slip during surgery. At an average follow-up period of

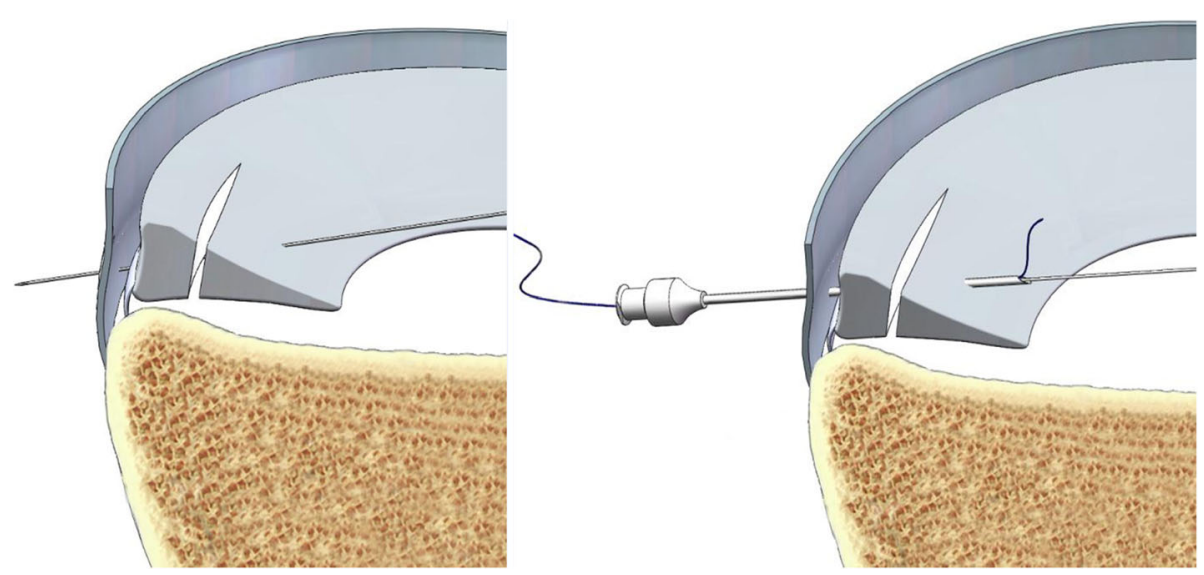

Fig. 5 The needle can be guided by a K-wire using the inside-out technique for the repair of tears of the posterior horn of the medial meniscus (left knee) 
13 months, there were no cases of post-operative meniscal symptoms and joint line tenderness. A total of $12 \mathrm{pa}$ tients with anterior or posterior cruciate ligament reconstruction reviewed magnetic resonance image and underwent a second evaluation under arthroscopy, and completely healed meniscal tears were observed.

\section{Discussion}

Meniscal function is essential for normal function of the knee joint. The meniscus is responsible for load transmission and shock absorption of the tibiofemoral joint in the human knee [22]. In addition, it acts as a secondary anteroposterior stabilizer of the knee joint, contributing to proprioception of the knee joint, lubrication, and supply of nutrition to the articular cartilage [22]. The purpose of surgical treatment is to promote meniscal healing and restore the function of the meniscus as much as possible.

Although there are many techniques for meniscus suture technique, the failure rate of the meniscal repair increases from early to long-term follow-up [23], especially for younger patients [24]. The failure rate of medial meniscal sutures has been reported in a systematic review to be $22.3-24.3 \%$ for all techniques investigated for 5 years postoperatively [15]. Some anatomical and biomechanical explanations for this high failure rate include blood supply and motion [25-27], but also repair technique factors such as high fixation strength, stability, and tension [28]. The fixation strength required to maintain the meniscus in a reduced position during ambulation and rehabilitation should be considered for long, complex, degenerative tears, and tears, especially in older patients [29]. However, the meniscus has inherent activity during motion of the knee joint [30, 31]. If the meniscus cannot move with knee activity, it may be caught between the condyle of the femur and the plateau of the tibia, thereby causing injury.

The traditional outside-in and inside-out repair techniques do not simply repair the meniscus itself, which also used to suture the meniscus, joint capsule, and subcutaneous tissues together. Excessive extra-articular tissue and nerve endings being knotted will increase the pulling of the meniscus and can even cause pain.
Furthermore, these knots could change the normal anatomy and biomechanics, which could limit the activity of the meniscus during motion and increase the chance of meniscal injury. Another disadvantage of this technology is that it will leave a knot outside the capsule. Some patients often complain of knot prominence since the incisions are on the sides of the knee where the extracapsular tissue layers are thin. The all-inside repair technique with meniscal fixators has been increasingly popular for the posterior horns and middle segments of the meniscus. However, several material-related complications have been reported [12-14]. Parts of the all-inside suture materials had to be removed in some cases because of persistent irritative symptoms [32-35]. Several bioabsorbable devices, which facilitate all-inside meniscal repair (arrows, staples), have been devised, but their use has not been indicated in any tear configuration. We use absorbable PDS suture to sew the meniscus in the present study, which was proved that has superior resistance to failure compared with the other suture types (Ethibond) for vertical mattress technique [36]. In addition, cyst formation has also been reported. Choi et al. [37] found an overall $8 \%$ incidence of cyst generation, and Hoffelner et al. [38] found an overall 11.1\% incidence in their study. Terai [39] found that cyst formation occurred in $29 \%$ of those in which the Fast Fix was used.

The present repair technology is an improvement of the traditional outside-in and all inside repair technology, which could be used to suture or bind the true meniscus tissue, thereby avoiding the joint capsule and subcutaneous tissue being knotted. It could be used to strongly hold the torn meniscus tissue without limiting the motion of the meniscus itself, while also preserving the inherent activity of the meniscus (Table 1).

Compared with other methods, this technology has the following advantages (Table 2). First, this is a simple and fast repair technique that only requires a needle and a suture. There is no need to use other expensive materials, which reduces the cost of surgery for patients. Secondly, the current technique is a minimally invasive procedure. The whole process can be completed through the routine arthroscopic portal, without the need to

Table 1 the pearls and pitfalls of the present technique

\begin{tabular}{ll}
\hline Pearls & Pitfalls \\
\hline Suturing the true meniscus tissue without excessive extra-articular tissue & The tied knot should be positioned towards the peripheral rim portion of \\
and nerve endings being knotted could reduce pain after postoperative. & the meniscosynovial junction to prevent articular cartilage erosion of the \\
Stable fixation during operation & femoral condyle during motion. \\
Preserving the inherent activity of the meniscus & A K-wire to guide the meniscal repair needle or pie-crusting tecnique for \\
Knotting under arthroscopy avoid meniscus curl and eversion. & tears of the posterior horn of the medial meniscus. \\
Arthroscopic visualization assess the proper tension of the suture repair. & other techniques such as hook suture should be selected for the posterior \\
& horn of the lateral meniscus. \\
\hline
\end{tabular}


Table $\mathbf{2}$ the advantages and disadvantages

\begin{tabular}{ll}
\hline Advantages & Disadvantages \\
\hline Minimally invasive technique & $\begin{array}{l}\text { High technical requirements } \\
\text { Routine arthroscopic approach }\end{array}$ \\
$\begin{array}{l}\text { Low-cost } \\
\text { Potential risks of injury to neurovascular structures for the posterior horn of the lateral } \\
\text { meniscus } \\
\text { Anatomic reduction }\end{array}$ & $\begin{array}{l}\text { Difficult for posterior horn of the medial meniscus because of narrow space } \\
\text { No knot leave a knot outside the capsule or } \\
\text { subcutaneous }\end{array}$ \\
No material-related complications & \\
\hline
\end{tabular}

create additional portal and skin incisions. Thirdly, the tension can be adjusted as needed during knotting. Lastly, this is an anatomical suturing procedure, resulting in high fixation strength. This technique could be used to suture the true meniscus tissue without the capsule and subcutaneous tissue, and could preserve inherent activity of the meniscus, decreasing the chance of meniscal re-injury.

There were some risks and limitations for this technique. Firstly, there is a potential risk of neurovascular injury if it was used to suture the posterior horn of the lateral meniscus. For this reason, other techniques such as hook suture should be selected for the posterior horn of the lateral meniscus. Secondly, during the process of penetrating, there is a risk that the suture material may be cut by the beveled needle tip. Using our custom-designed meniscal repair needle can effectively avoid this problem. Cartilage injury may be another risk when suturing the posterior horn of the medial meniscus due to narrow joint space. This problem can be effectively avoided by using a Kwire to guide the meniscal repair needle or piecrusting tecnique. It can ensure ensure accurate penetrate and reduce the risk of cartilage injury during surgery. Of course, there are some other risks such as incision infection, meniscus re-injury, which can be avoided with sterile operations and standard rehabilitation exercises. In addition, according to the type of meniscus tear, this technique can also be used in combination with other methods. For example, we can use this method together with all-inside technique to repair bucket-handle meniscus tear. At last, further prospective clinical studies and biomechanical tests of this technique are needed in the future.

\section{Conclusions}

In conclusion, the technique presented here is suitable for most parts of the meniscus except for the posterior horn of the lateral meniscus. We believe that this technique could provide a good alternative for sports medicine doctors.

\section{Supplementary information}

Supplementary information accompanies this paper at https://doi.org/10. 1186/s12891-019-2984-3.

Additional file 1: Video S1. The process of suturing process of the posterior horn of the medial meniscus (left knee) under arthroscope. First, a meniscal repair needle with 2 PDS suture penetrated the capsular portion, crossing the tibial surface of the meniscus, and entered the joint cavity. Secondly, the suture tip was retrieved through the arthroscopy portal using a probe. Thirdly, the needle was withdrawn along the suture to the synovial margin of the meniscus inside the capsule and reinserted upwards without penetrating the meniscus tissue, exiting the femoral surface of the torn meniscus. The suture was pulled out with a probe. Next, the two limbs of the suture were retrieved through the same arthroscopy portal using a grasper and formed a sliding knot inside the joint. Additional knots were made to secure the knot. The suture strands were cut by knot cutter and then he knot was pushed towards the peripheral rim portion of the meniscosynovial junction.

\section{Acknowledgements}

Not applicable.

\section{Authors' contributions}

$J$ and GC designed this study; ZQW and YX wrote the manuscript; XT, QL and ZZ was responsible for drawing. All authors reviewed the final manuscript. All authors agreed to be accountable for all aspects of the work. All authors read and approved the final manuscript.

\section{Funding}

This study was supported by 1.3.5 project for disciplines of excellence, West China Hospital, Sichuan University (ZY2917301); the Natural Science Foundation of China (81802176). The funding agency had no role in the design of the study and collection, analysis, and interpretation of data and in writing the manuscript.

\section{Availability of data and materials}

The datasets used and/or analyzed during the current study are available from the corresponding author on reasonable request.

\section{Ethics approval and consent to participate}

This study was approved by the Ethics Committee of West China Hospital, Sichuan University. Written, informed consent was obtained from each participant.

\section{Consent for publication}

Not applicable.

\section{Competing interests}

The authors declare that they have no competing interests.

\section{Author details}

${ }^{1}$ Department of Orthopaedic Surgery, West China Hospital, Sichuan University, No. 37, Guoxue Alley, Chengdu 610041, China. '2Department of 
Orthopaedic Surgery, Suining Central Hospital, No. 127, West Desheng Rd., Chuanshan District, Suining, Sichuan 629000, China.

Received: 17 July 2019 Accepted: 2 December 2019

Published online: 23 December 2019

\section{References}

1. Hede A, Jensen DB, Blyme P, Sonne-Holm S. Epidemiology of meniscal lesions in the knee. 1,215 open operations in Copenhagen 1982-84. Acta Orthop Scand. 1990;61(5):435-7.

2. Roos $H$, Lauren $M$, Adalberth $T$, Roos EM, Jonsson K, Lohmander LS. Knee osteoarthritis after meniscectomy: prevalence of radiographic changes after twenty-one years, compared with matched controls. Arthritis Rheum. 1998; 41(4):687-93.

3. Bender B, Shabat S, Mann G, Oz H, Adar E. The double-loop technique for meniscal suture. Arthroscopy. 2002;18(8):944-7.

4. Laupattarakasem W, Sumanont S, Kesprayura S, Kasemkijwattana C. Arthroscopic outside-in meniscal repair through a needle hole. Arthroscopy. 2004;20(6):654-7.

5. Petsche TS, Selesnick H, Rochman A. Arthroscopic meniscus repair with bioabsorbable arrows. Arthroscopy. 2002;18(3):246-53.

6. Selby RM, Altchek DW, Di Giacomo G. The Di Giacomo technique: simplified suture passing in SLAP repair. Arthroscopy. 2007;23(4):439.e431-2.

7. Miller MD, Hart JA. All-inside meniscal repair. Instr Course Lect. 2005;54:337-40.

8. Cho JH. A modified outside-in suture technique for repair of the middle segment of the meniscus using a spinal needle. Knee Surgery Relat Res. 2014;26(1):43-7.

9. Johnson D, Weiss B. Meniscal repair using the inside-out suture technique Sports Med Arthrosc Rev. 2012;20(2):68-76.

10. Complications in arthroscopy: the knee and other joints. Committee on Complications of the Arthroscopy Association of North America. Arthroscopy. 1986;2(4):253-8.

11. Cuellar A, Cuellar R, Cuellar A, Garcia-Alonso I, Ruiz-Iban MA. The effect of knee flexion angle on the neurovascular safety of all-inside lateral meniscus repair: a cadaveric study. Arthroscopy. 2015;31(11):2138-44.

12. Miller MD, Kline AJ, Gonzales J, Beach WR. Pitfalls associated with FasT-fix meniscal repair. Arthroscopy. 2002;18(8):939-43.

13. Seil R, Rupp S, Dienst M, Mueller B, Bonkhoff H, Kohn DM. Chondral lesions after arthroscopic meniscus repair using meniscus arrows. Arthroscopy. 2000;16(7):E17.

14. Song EK, Lee KB, Yoon TR. Aseptic synovitis after meniscal repair using the biodegradable meniscus arrow. Arthroscopy. 2001;17(1):77-80.

15. Nepple JJ, Dunn WR, Wright RW. Meniscal repair outcomes at greater than five years: a systematic literature review and meta-analysis. J Bone Joint Surg Am. 2012;94(24):2222-7.

16. Kim TK, Savino RM, MCFarland EG, Cosgarea AJ. Neurovascular complications of knee arthroscopy. Am J Sports Med. 2002:30(4):619-29.

17. Mullen DJ, Jabaji GJ. Popliteal pseudoaneurysm and arteriovenous fistula after arthroscopic meniscectomy. Arthroscopy. 2001;17(1):E1.

18. Allum R. Complications of arthroscopy of the knee. J Bone Joint Surg Br Vol. 2002;84(7):937-45.

19. Cohen SB, Boyd L, Miller MD. Vascular risk associated with meniscal repair using Rapidloc versus FasT-fix: comparison of two all-inside meniscal devices. J Knee Surg. 2007:20(3):235-40

20. Moulton SG, Bhatia S, Civitarese DM, Frank RM, Dean CS, LaPrade RF. Surgical techniques and outcomes of repairing meniscal radial tears: a systematic review. Arthroscopy. 2016;32(9):1919-25.

21. Stärke C, Kopf S, Petersen W, Becker R. Meniscal Repair. Arthroscopy. 2009; 25(9):1033-44

22. Walker PS, Erkman MJ. The role of the menisci in force transmission across the knee. Clin Orthop Relat Res. 1975;109:184-92.

23. Lee GP, Diduch DR. Deteriorating outcomes after meniscal repair using the meniscus arrow in knees undergoing concurrent anterior cruciate ligament reconstruction: increased failure rate with long-term follow-up. Am J Sports Med. 2005:33(8):1138-41.

24. Krych AJ, Reardon P, Sousa P, Levy BA, Dahm DL, Stuart MJ. Clinical outcomes after revision meniscus repair. Arthroscopy. 2016:32(9):1831-7.

25. Ahn JH, Bae TS, Kang KS, Kang SY, Lee SH. Longitudinal tear of the medial meniscus posterior horn in the anterior cruciate ligament-deficient knee significantly influences anterior stability. Am J Sports Med. 2011;39(10):2187-93.
26. Thompson WO, Thaete FL, Fu FH, Dye SF. Tibial meniscal dynamics using three-dimensional reconstruction of magnetic resonance images. Am J Sports Med. 1991;19(3):210-5 discussion 215-216.

27. Allen CR, Wong EK, Livesay GA, Sakane M, Fu FH, Woo SL. Importance of the medial meniscus in the anterior cruciate ligament-deficient knee. J Orthop Res. 2000;18(1):109-15.

28. Majewski M, Stoll R, Widmer H, Muller W, Friederich NF. Midterm and longterm results after arthroscopic suture repair of isolated, longitudinal, vertical meniscal tears in stable knees. Am J Sports Med. 2006;34(7):1072-6.

29. Abdelkafy A. Modified cruciate suture technique for arthroscopic meniscal repair: a technical note. Knee Surg Sports Traumatol Arthrosc. 2007;15(9):1116-20.

30. Sim FH. The knee: form, function, and ligament reconstruction. Mayo Clin Proc. 1984;59(1):55

31. Bylski-Austrow DI, Ciarelli MJ, Kayner DC, Matthews LS, Goldstein SA Displacements of the menisci under joint load: an in vitro study in human knees. J Biomech. 1994;27(4):421-31.

32. Hantes ME, Zachos VC, Varitimidis SE, Dailiana ZH, Karachalios T, Malizos KN. Arthroscopic meniscal repair: a comparative study between three different surgical techniques. Knee Surg Sports Traumatol Arthrosc. 2006;14(12):1232-7.

33. Jones HP, Lemos MJ, Wilk RM, Smiley PM, Gutierrez R, Schepsis AA. Twoyear follow-up of meniscal repair using a bioabsorbable arrow. Arthroscopy. 2002;18(1):64-9.

34. Kurzweil PR, Tifford CD, Ignacio EM. Unsatisfactory clinical results of meniscal repair using the meniscus arrow. Arthroscopy. 2005:21(8):905.

35. Tsai AM, McAllister DR, Chow S, Young CR, Hame SL. Results of meniscal repair using a bioabsorbable screw. Arthroscopy. 2004;20(6):586-90.

36. Post WR, Akers SR, Kish V. Load to failure of common meniscal repair techniques: effects of suture technique and suture material. Arthroscopy. 1997;13(6):731-6 (0749-8063 (Print)).

37. Choi N-H, Kim B-Y, Hwang Bo B-H, Victoroff BN. Suture versus FasT-fix allinside meniscus repair at time of anterior cruciate ligament reconstruction. Arthroscopy. 2014;30(10):1280-6.

38. Hoffelner $T$, Resch $H$, Forstner $R$, Michael M, Minnich B, Tauber M. Arthroscopic all-inside meniscal repair-does the meniscus heal? Skelet Radiol. 2010:40(2):181-7.

39. Terai S, Hashimoto Y, Yamasaki S, Takahashi S, Shimada N, Nakamura H. Prevalence, development, and factors associated with cyst formation after meniscal repair with the all-inside suture device. Arch Orthop Trauma Surg. 2019;139(9):1261-8.

\section{Publisher's Note}

Springer Nature remains neutral with regard to jurisdictional claims in published maps and institutional affiliations.

Ready to submit your research? Choose BMC and benefit from:

- fast, convenient online submission

- thorough peer review by experienced researchers in your field

- rapid publication on acceptance

- support for research data, including large and complex data types

- gold Open Access which fosters wider collaboration and increased citations

- maximum visibility for your research: over $100 \mathrm{M}$ website views per year

At BMC, research is always in progress.

Learn more biomedcentral.com/submissions 